\title{
DOUBLE FLUX ORIENTATION CONTROL FOR A DOUBLY FED INDUCTION GENERATOR BASED WIND TURBINE.
}

\author{
N. Hamdi ${ }^{1}$, A. Bouzid ${ }^{2}$ \\ Electrical Laboratory of Constantine "LEC”, Department of Electrical Engineering, Mentouri University - Constantine, \\ 25000 Constantine, ALGERIA, hamdi_naouel@yahoo.fr,you.bouzid@yahoo.fr
}

\begin{abstract}
Abstract In this paper we present a new strategy of vector control for variable speed wind turbines (WT) based on Doubly-Fed Induction Generator (DFIG). It is based on the principle of a double flux orientation (DFOC) of stator and rotor at the same time. This one creates the orthogonally between the two oriented fluxes, which must be strictly observed, and therefore leads to generate a linear and decoupled control of the active and reactive powers. The simulation was performed using Simulink of Matlab to show the effectiveness of the proposed control strategy.
\end{abstract}

Index Terms: Doubly fed induction generator (DFIG), wind turbine (WT), double flux Orientation control, vector control. $* * *$

\section{INTRODUCTION}

Wind energy is the way of electrical generation from renewable sources which uses wind turbines, concentrated in wind farms, to convert the energy contained in flowing air into electrical energy. Wind power is the world's fastest growing energy source with a growing at an annual rate in excess of $30 \%$ and a foreseeable penetration equal to $12 \%$ of global electricity demand by $2020[1,2]$.

The DFIG has some advantages compared to the conventional squirrel-cage machine. It can be controlled from the stator or rotor by various possible combinations. Indeed, the inputcommands are done by means of four precise degrees of control freedom relatively to the squirrel cage induction machine where its control appears quite simpler [11]. The flux orientation strategy can transform the non linear and coupled DFIM-mathematical model to a linear model leading to one attractive solution as well as under generating or motoring operations $[3,10]$.

The main idea behind all flux orientation control strategies is that the machine flux position or vector flux components are computed from the direct physic measurements. In DFIM, both stator and rotor currents are easily measured [4].

The paper is organised as follows: In section II, the DFIG model in an arbitrary reference-frame is presented. In section III the turbine wind model is presented. In section IV the control strategy for this system is proposed. Finally, the results and conclusions are drawn.

\section{MATHEMATICAL MODEL OF THE DFIG}

The equivalent two-phase model of the symmetrical DFIG, represented in an arbitrary rotating $\mathrm{d}-\mathrm{q}$ reference frame is [3 $, 5,6,7]$ :

$$
\begin{aligned}
& V_{s d}=R_{s} i_{s d}+\frac{d \phi_{s d}}{d t}-\frac{d \theta_{s}}{d t} \phi_{s q} \\
& V_{s q}=R_{s} i_{s q}+\frac{d \phi_{s q}}{d t}+\frac{d \theta_{s}}{d t} \phi_{s d} \\
& V_{r d}=R_{r} i_{r d}+\frac{d \phi_{r d}}{d t}-\frac{d \theta_{r}}{d t} \phi_{r q} \\
& V_{r q}=R_{r} i_{r q}+\frac{d \phi_{r q}}{d t}+\frac{d \theta_{r}}{d t} \phi_{r d}
\end{aligned}
$$

The Stator and rotor fluxes are given as:

$$
\begin{aligned}
& {\left[\begin{array}{l}
\phi_{s d} \\
\phi_{r d}
\end{array}\right]=\left[\begin{array}{cc}
L_{s} & M_{s r} \\
M_{r s} & L_{r}
\end{array}\right] \cdot\left[\begin{array}{l}
i_{s d} \\
i_{r d}
\end{array}\right]} \\
& {\left[\begin{array}{l}
\phi_{s q} \\
\phi_{r q}
\end{array}\right]=\left[\begin{array}{cc}
L_{s} & M_{s r} \\
M_{r s} & L_{r}
\end{array}\right] \cdot\left[\begin{array}{c}
i_{s q} \\
i_{r q}
\end{array}\right]}
\end{aligned}
$$

The electromagnetic torque is expressed as:

$$
\begin{aligned}
& C_{e m}=\frac{3}{2}\left(\phi_{s d} i_{s q}-\phi_{s q} i_{s d}\right) \\
& p=V_{s d} i_{s d}+V_{s q} i_{s q} \\
& Q=V_{s q} i_{s d}-V_{s d} i_{s q}
\end{aligned}
$$




\section{WIND TURBINE MODEL}

The air tube around a wind turbine is illustrated in Figure 1. Assuming that the wind speed (V1) crossing the rotor is the average value between the upstream speed (V0) and the downstream speed (V2), the moving air mass of density $\rho$ crossing the surface $S(S=\pi R 2)$ per unit of time is given by [9]:

$m=\frac{\pi \rho R^{2}\left(V_{0}+V_{2}\right)}{2}$

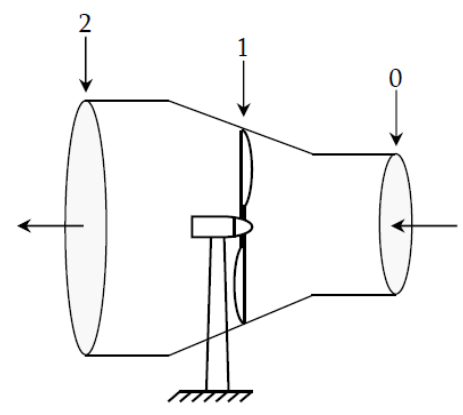

Fig -1: Air tube around the wind turbine

By applying the conservation of mass to the case of the Fig.1 we have:

$\mathrm{V}_{0} S_{0}=V_{1} S_{1}=V_{2} S_{2}$

Where $\mathrm{Vi}$ is the wind speed at station $\mathrm{i}$ and $S_{i}$ is the cross section area of station i. It is considered thereafter that $V=V_{1}$ et $S=S_{1}$

The pressure force of the turbine rotor is given by:

$F=\rho S_{0} V_{0}^{2}-\rho S_{2} V_{2}^{2}$

Or equivalently, using Eq. (8):

$F=\rho S V\left(V_{0}-V_{2}\right)$

Assuming that the speed of the wind crossing the rotor is equal to the average between the non-disturbed speed of the wind in the front one the turbine $V_{0}$ and the speed of the wind after the passage through the rotor $V_{2}$, that is to say:

$V=\frac{V_{0}+V_{2}}{2}$

And customarily defining an axial induction (or interference) factor, a, as the fractional decrease in wind velocity between position 0 and position 1 , by:
$a=\frac{V_{0}-V}{V_{0}}$

Eq. (10) can be rewritten in a more useful manner:

$F=\frac{1}{2} \rho S V_{0}^{2} 4 a(1-a)$

The wind power extracted by the rotor is the product of the pressure forces the turbine rotor and the speed of the wind in the plan of the rotor:

$P_{t u}=F V=\frac{1}{2} \rho S V_{0}^{2} 4 a(1-a) V_{0}(1-a)=\frac{1}{2} \rho S V_{0}^{3} 4 a(1-a)^{2}$

Theoretically, a non-disturbed wind crosses this same surface $S$ without reduction of the speed which is $V_{0}$, the corresponding theoretical power $P_{t h}$ would be then:

$P_{t h}=\frac{1}{2} \rho S V_{0}^{3}$

The ratio between $P_{t h}$ and $P_{t u}$, called the power coefficient $\mathrm{Cp}$ is then:

$C_{p}=\frac{P_{t u}}{P_{t h}}=4 a(1-a)^{2}$

The result is shown in Fig. 2.

The power coefficient has a maximum $C_{\text {pmax }} \approx 0.59$. This theoretical value is well-known as 'Betz limit' which determines the maximum power that can be extracted from a given wind speed. This limit cannot be reached in reality. Therefore, each wind turbine is defined by its appropriate $\mathrm{Cp}$ versus the tip-speed ratio $\lambda$, where:

$\lambda=\frac{\Omega_{\text {turbine }} \cdot R}{v}$

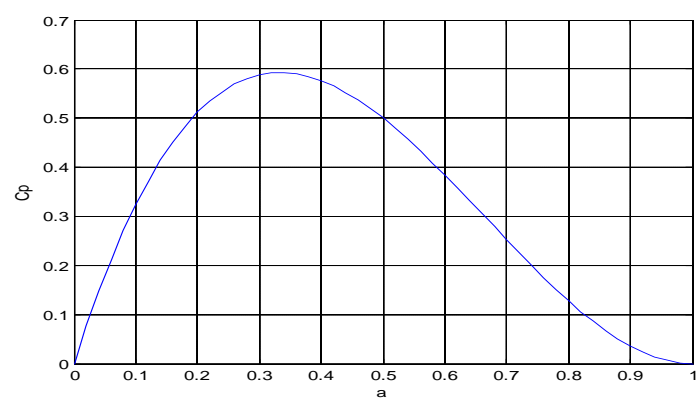

Fig -2: Power coefficient versus wind speed ratio 
The mechanical power will be written then:

$$
P_{t u}=P_{t h} C_{p}(\lambda)=C_{p}(\lambda) \frac{R^{2} \rho \pi V_{0}^{3}}{2}
$$

This expression allows obtaining a set of characteristics presenting the generator mechanical power depending both on the wind and rotating speeds. The result is shown in Fig.3.

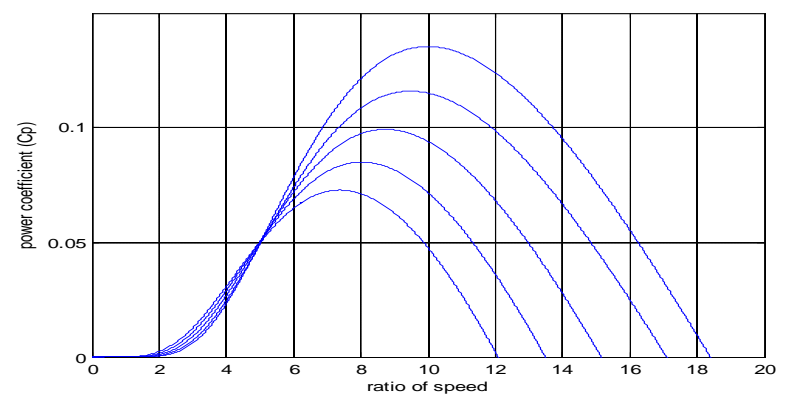

Fig-3: Characteristics of mechanical power versus wind and rotating speeds

\section{DOUBLE FLUX ORIENTATION STRATEGY}

This strategy consists to turn the rotor flux towards d axis, and the stator flux towards q axis. After orientation the stator and rotor fluxes are presented in Fig. 4

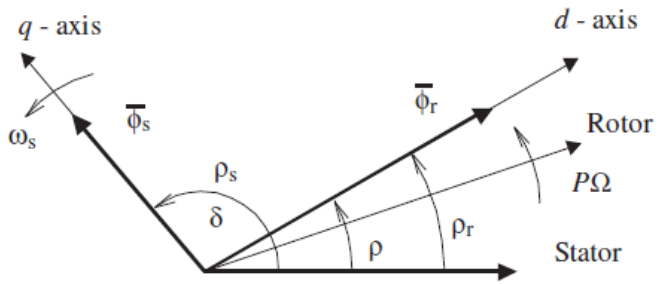

Fig-4: DFIG vector after orientation

Consequently, the two fluxes become orthogonal and we can write:

$\phi_{s q}=\phi_{s}$

$\phi_{r d}=\phi_{r}$

$\phi_{s d}=\phi_{r q}=0$

If resistance $R_{s}$ is neglected we have:

$V_{s q}=\frac{d \phi_{s q}}{d t}=0$

$V_{s d}=V_{s}$
Introducing Using (19) in (6) the developed active power and reactive power can be rewritten as follows:

$$
\begin{aligned}
& P=V_{s} i_{s d} \\
& Q=-V_{s} i_{s q}
\end{aligned}
$$

Where:

$$
\begin{aligned}
& i_{s d}=-\frac{M_{s r}}{L_{s}} i_{r d} \\
& i_{s q}=-\frac{L_{r}}{M_{s r}} i_{r q}
\end{aligned}
$$

Where:

$$
\begin{aligned}
& P=-V_{s} \frac{M_{s r}}{L_{s}} i_{r d} \\
& Q=V_{s} \frac{L_{r}}{M_{s r}} i_{r q}
\end{aligned}
$$

\section{SIMULATION RESULTS}

The system described above is simulated using Matlab SimulinkTM.

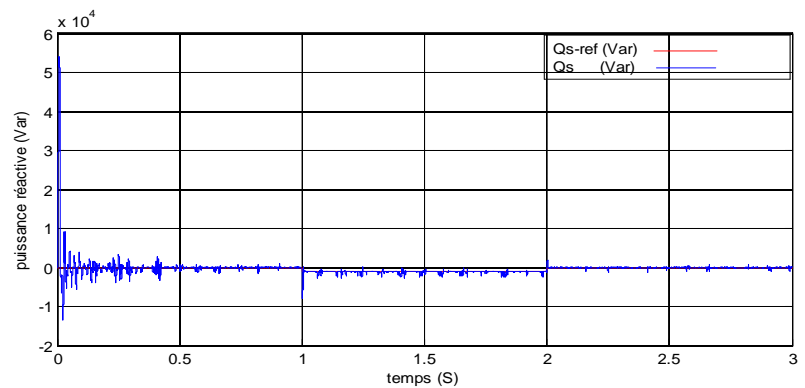

Fig -5: Reactive power versus time.

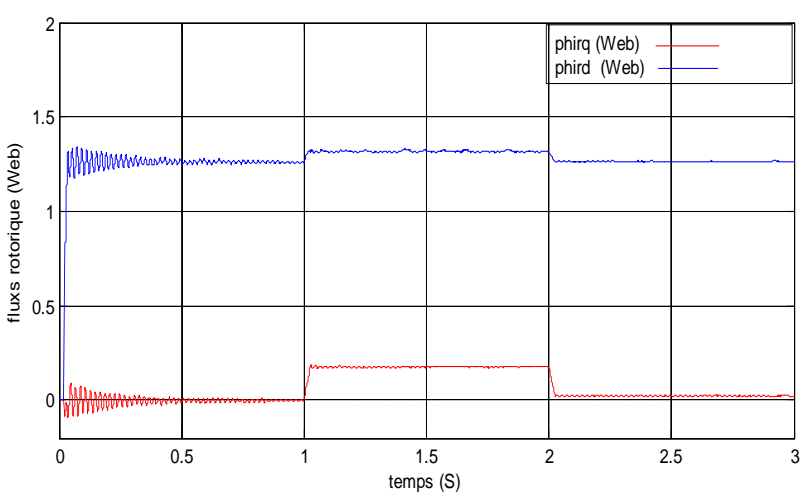

Fig-6: Active power versus time 


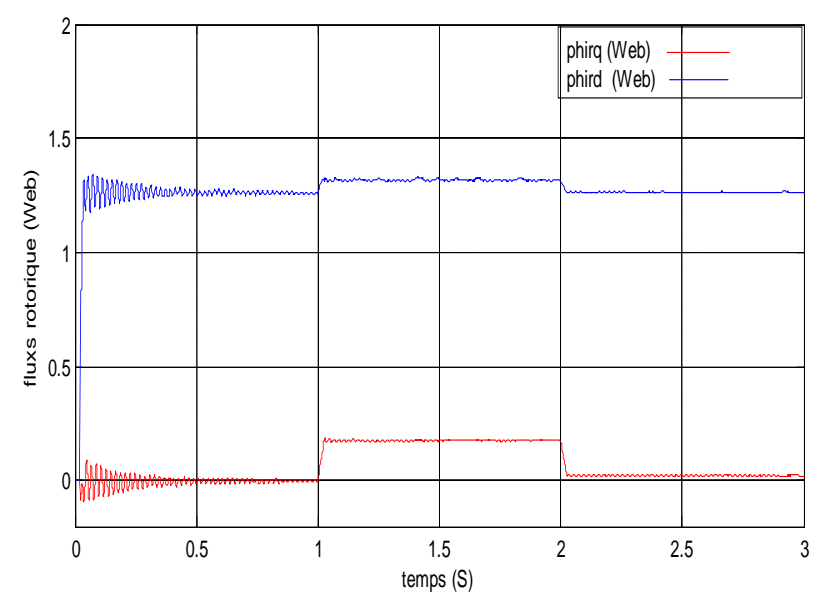

Fig.7: Rotor fluxes versus time.

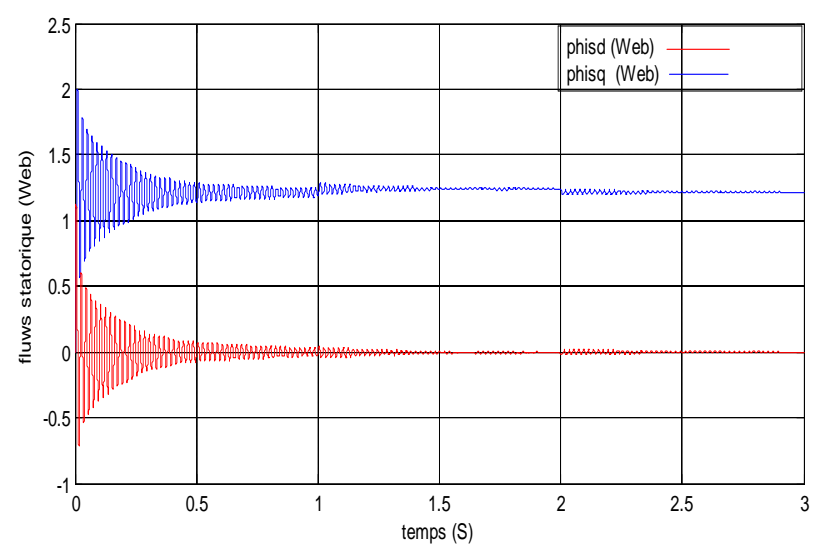

Fig-8: Stator fluxes versus time.

We see in fig.5and Fig.6 that the corresponding power follows the reference signal from $0.21 \mathrm{~s}$. In fig.7 and fig.8, the stator and rotor fluxes are presented versus time and where we can observe clearly the fluxes orientation strategy. Thus show the effectiveness of the proposed control strategy.

\section{CONCLUSIONS}

Access to the stator and rotor windings is one of the advantages of the wound rotor induction machine compared to the conventional squirrel-cage machine. The DFIG offers the possible control of the active and reactive powers. The simulations results of this strategy control present clearly the orientation of fluxes of the stator and rotor with respect to time. The first advantage of this strategy is the transformation of the nonlinear and coupled DFIG mathematical model to a linear and decoupled one. The second advantage consists of the non use of a controller. The simulation results prove that the proposed wind power generator is feasible and has certain advantages.

\section{NOMENCLATURE}

$P, Q \quad$ Stator active and reactive powers.

$V_{s d}, V_{s q} \mathrm{~d}$ - and q-axis components of the stator voltage.

$V_{r d}, V_{r q} \mathrm{~d}$-and q -axis components of the rotor voltage.

$i_{s q}, i_{s q} \mathrm{~d}$ - and q-axis components of the stator current.

$i_{r d}, i_{r q}$ d-and q-axis components of the rotor current.

$R_{s}$ Stator phase resistance.

$R_{r}$ Rotor phase resistance.

$M_{s r}$ Mutual inductance between the stator and rotor.

$L_{s}$ Stator inductance.

$L_{r} \quad$ Rotor inductance.

$P \quad$ Number of poles of the induction machine.

$\omega_{s}$ Stator pulsation.

$\omega_{r}$ Rotor pulsation.

$C_{e m}$ Electromagnetic torque.

$\phi_{s d}, \phi_{s q} \mathrm{~d}$ - and q-axis components of the stator flux linkage.

$\phi_{r d}, \phi_{r q} \mathrm{~d}$ - and q-axis components of the rotor flux linkage.

\section{REFERENCES:}

[1]. C. Millais and S. Teske (2004, May). Wind Force 12: A blueprint to achieve $12 \%$ of the world's electricity fromwind power by 2020.Greenpeace and European Wind Energy Association [Online].Avalable:

http://www.ewea.org/03publications/WindForce12.htm.

[2]. S. Muller, M. Deicke, and R. W. De Doncker., "Doubly fed induction generator systems for wind turbines," IEEE Industry Applications Magazine, pp. 26-33, May/June 2002.

[3]. M. G. Simões, B. K. Bose, and R. J. Spiegel, "Fuzzy logic based intelligent control of a variable speed cage machine wind generation system," IEEE Trans. Power Electron., vol. 12, pp. 87-95, Jan. 1997

[4]. Said Drid, Mohamed Tadjine, Mohamed-Said Nait-Said: "Nonlinear feedback control and torque optimization of a doubley fed induction motor" Journal of ELECTRICALENGINEERING, VOL. 56, NO. 3-4, 2005, $57-63$

[5]. Herrera, J.I. and Reddoch, T.W.; "Analysis of The Electrical Characteristics of a Westinghouse Variable Speed Generating System for Wind Turbine Applications" SERI/STR-217-3133, DE88001139, February 1988.

[6]. WANG, S.-DING, Y. : Stability Analysis of Field Oriented Doubly Fed Induction Machine Drive Based on Computed Simulation, Electrical Machines and Power Systems (Taylor \& Francis), 1993.Z. Chilengue, 
[7]. R. S. Peña, J. C. Clare, and G. M. Asher, "Vector control of a variable speed doubly-fed induction machine for wind generation systems," EPEJ., vol. 6, no. 3-4, pp. 60-67, Dec. 1996.

[8].T. Tanaka, T. Toumiya, and T. Suzuki, "Output control by hill-climbing method for a small scale wind power Generating system," Renewable Energy, vol. 12, no. 4, pp. 387-400, 1997.

[9].POITIERS F. "Etude et Commande de Génératrices Asynchrones pour l'Utilisation de l'Energie Eolienne" .Thèse de l'Ecole Polytechnique de l'Université de Nantes, Nantes, France, 2003.

[10].F. Valenciaga and P. F. Puleston, "Variable structure control of a wind energy conversion system based on a brushless doubly fed reluctance generator," IEEE Transaction on Energy Conversion, vol. 22, pp. 499- 506, June 2007.

[11].B. T. Ooi and R. A. David, "Inductiongenerator/synchronous-condenser system for wind- turbine power," Proc. Inst. Elect. Eng., vol. 126, no. 1,pp . 69- 74, Jan. 1979

\title{
BIOGRAPHIES:
}

N. Hamdi Was born in Constantine, Algeria, in 1976, in 2003 received the Engineer degree from the University of Montouri Constantine. Algeria. In 2008 received the M.S. degrees in electrical engineering, Option electrical machine. . In 2008 inscription in doctor's degree.

\begin{abstract}
Aissa Bouzid was born in Constantine, Algeria, in1954. He received the diploma of electrotechnology engineer in 1980 at the science and Technology University of Algiers, Master degree electronics, (1985) and his $\mathrm{PhD}$ in Electrotechnology from Orsay University of Paris in France (1994). Since 1996 he has been a Professor, at the Faculty of Engineering, University Mentouri of Constantine. His main scientific interests are in the fields of circuit theory and applications and power electronics, also his study is about the photovoltaic systems and their applications
\end{abstract}

